\title{
A Human B cell Receptor Epitope-Based erbB-2 Peptide (N: 163-182) with Pan-Reactivity to the T cells of Japanese Breast Cancer Patients
}

Banri Tsuda ${ }^{1}$, Yoshie Kametani ${ }^{\star}$, Yumiko Goto ${ }^{3}$, Yuki Saito ${ }^{1}$, Yasuhiro Suzuki ${ }^{1}$, Sonoko Habu ${ }^{4}$, Hidetoshi Inoko ${ }^{5}$ and Yutaka Tokuda $^{1}$

${ }^{1}$ Department of Breast surgery, Tokai University School of Medicine, Kanagawa, Japan

${ }^{2}$ Department of Immunology, Tokai University School of Medicine, Kanagawa, Japan

${ }^{3}$ Department of Gynecology, Tokai University School of Medicine, Kanagawa, Japan

${ }^{5}$ Department of Molecular Life Science, Tokai University School of Medicine, Kanagawa, Japan

${ }^{4}$ Department of Immunology, Juntendo University School of Medicine, Tokyo, Japan

\begin{abstract}
Background: While monoclonal antibodies are widely accepted as being powerful in molecular targeting therapy, the activation of immunity by the B cell receptor epitope peptide has not been reported. Our objective was to evaluate a 20-mer multiple antigen peptide containing the anti-erbB-2 (HER2/neu) monoclonal antibody epitope (N: 163-182), designated as CH401MAP, as a general peptide vaccine for Japanese breast cancer patients.

Methods: The 20-mer CH401 epitope peptide binding to the human leukocyte antigen (HLA) of Japanese breast cancer patients was predicted by algorithms from the following databases: SYFPEITHI, Bioinformatics and Molecular Analysis Section (BIMAS), and Immune Epitope Database (IEDB). Peripheral blood mononuclear cells (PBMCs) were collected from 173 breast cancer patients and stimulated with the peptide in vitro. Cytokine secretion was examined by enzyme-linked immunosorbent assay (ELISA). Flow cytometric analysis was performed to detect CD4 and CD8 T cells and Treg cells.

Results: Using the algorithms used for the simulation, CH401MAP was predicted to bind to more than $90 \%$ of class I HLAs and to $30-50 \%$ of class II HLAs in breast cancer patients. In vitro stimulation of patients' PBMCs with CH401MAP induced a significant increase in interleukin-2 secretion, proliferation, and CD8 T cell ratios.

Conclusions: Our study demonstrates that CH401MAP induces T cell activation in PBMCs derived from breast cancer patients. This antibody epitope-based peptide with HLA motifs could be a candidate peptide vaccine for general breast cancer.
\end{abstract}

Keywords: CH401; Breast cancer; HER2; Peptide vaccine; B cell epitope

Abbreviations: HER2: Human Epidermal Growth Factor Receptor 2; BIMAS: BioInformatics and Molecular Analysis Section; IEDB: Immune Epitope DataBase; PBMC: Peripheral Blood Mononuclear Cells; ELISA: Enzyme-linked Immunosorbent Assay; HLA: Human Leukocyte Antigen; PI3K: Phosphoinositide 3-kinase; CTLs: Cytotoxic Lymphocytes; MHC: Major Histocompatibility Complex; FISH: Fluoresence In Situ hybridization; HD: Healthy Donors; Mab: Monoclonal Antibody; MAP: Multiple Antigen Peptide; PBS: Phosphate Buffer saline; FCM: Flowcytometry; PE: Phycoerythrin; FITC: Fluorescein Isothiocyanate; PerCP-Cy5.5: Peridinin Chlorophyll Protein Complex-Cyanin-5.5; APC: Allophycocyanin; FOXP3: Forkhead box P3; SD: Standard Deviation

\section{Introduction}

Passive immune therapy with "trastuzumab" is a powerful tool for treating human epidermal growth factor receptor 2 (HER2)overexpressing breast cancers [1], which is observed in $20 \sim 30 \%$ of breast cancer patients [2]. HER2 positivity rate is similar between Japanese and Caucasians [3]. While amplification of the HER2 gene and overexpression of HER2 protein indicates rapid disease progression from early metastatic stages [4], trastuzumab treatment controls the progression of this type of breast cancer. However, several problems, such as occasional recurrence, occur under trastuzumab therapy, probably due to the acquisition of trastuzumab resistance. The mechanism of resistance acquisition has not been clarified, although Nahta et al. suggested that increased signaling via the phosphoinositide 3-kinase (PI3K)/Akt pathway might contribute to trastuzumab resistance [5]. Thus far, no means to overcome trastuzumab resistance have been reported. In the past decades, numerous attempts have been made to develop active immune therapies using appropriate peptide vaccines for breast cancer as an alternate or adjuvant of trastuzumab therapy. Some peptides, including GP2, E75, and AE37, were successively introduced into clinical trials [6-8]. However, to use these peptides for vaccination, it is crucial to determine the patients' human leukocyte antigen (HLA) types, because anchoring of the peptide to an individual's HLA is necessary to induce effective T cell activation with the peptide vaccines. However, limited types of HLA can present a specific peptide in general. Immunogenic peptides mentioned above (GP2, E75 and AE37) containing HER2 sequence can induce peptidespecific cytotoxic $\mathrm{T}$ lymphocytes (CTLs) that recognize tumor cells presenting themselves on major histocompatibility complex (MHC) class I molecules [9]. For example, the target of GP2 is HLA-2A, which is found in $45.8 \%$ of Caucasian, $39.0 \%$ of North American (NA) Black, $42.4 \%$ of Japanese, $45.9 \%$ of Chinese, and $43.0 \%$ of Hispanic

*Corresponding author: Yoshie Kametani Ph.D., Department of Immunology Tokai Univesity School of Medicine, 143, Shimokasuya, Isehara-shi, Kanagawa 259-1193, Japan, Tel: 081-463-93-1121 ext: 2589; Fax: 081-463-94-2976; E-mail: y-kametn@is.icc.u-tokai.ac.jp

Received October 05, 2012; Accepted November 18, 2012; Published November 22, 2012

Citation: Tsuda B, Kametani Y, Goto Y, Saito Y, Suzuki Y, et al. (2012) A Human B cell Receptor Epitope-Based erbB-2 Peptide (N: 163-182) with Pan-Reactivity to the $T$ cells of Japanese Breast Cancer Patients. J Vaccines Vaccin 3:159. doi:10.4172/2157-7560.1000159

Copyright: ( $) 2012$ Tsuda B, et al. This is an open-access article distributed unde the terms of the Creative Commons Attribution License, which permits unrestricted use, distribution, and reproduction in any medium, provided the original author and source are credited. 
Citation: Tsuda B, Kametani Y, Goto Y, Saito Y, Suzuki Y, et al. (2012) A Human B cell Receptor Epitope-Based erbB-2 Peptide (N: 163-182) with Pan-Reactivity to the T cells of Japanese Breast Cancer Patients. J Vaccines Vaccin 3:159. doi:10.4172/2157-7560.1000159

Page 2 of 6

populations [10]. HLA-A3 is found in $37.5 \%$ of Caucasian, $42.1 \%$ of NA Black, $45.8 \%$ of Japanese, $52.7 \%$ of Chinese, and $44.2 \%$ of Hispanic populations [10]. The targets of E75 are HLA-A2 and A3 [8]. None of these peptides can such a cover broad range of HLA types, including those of class I and class II.

Because the major HLA types are significantly different across races [10], it is necessary to select a peptide that binds to the HLA of patients of a particular race. Moreover, some results indicate that it is important to stimulate both CTLs and Th cells in order to acquire sufficient anticancer effect [11]. It is therefore imperative to develop a 'promiscuous' peptide vaccine, which is broadly restricted.

We previously reported a 20-mer peptide containing a B cell receptor epitope of anti-HER2 monoclonal antibody "CH401," which was reported to have apoptotic anticancer activity [12]. We named this peptide CH401MAP and proved that it can induce not only Th cell activation but also specific antibody production and Tc cell infiltration into HER2/neu-positive tumors in the $\mathrm{BALB} / \mathrm{c}$ mouse system. CH401MAP showed an antitumor effect against HER2-overexpressing mouse B cell lymphomas transplanted into BALB/c mice [13].

In this study, we predicted the human class I and class II HLA anchor motifs of CH401MAP and examined if the peptide is a "promiscuous" one. We found that $\mathrm{CH} 401 \mathrm{MAP}$ reacted with a vast majority of human lymphocytes of Japanese breast cancer patients, indicating the potential of a general breast cancer vaccine based on it in this population.

\section{Material and Methods}

\section{Cells from patients and healthy donors}

We enrolled 173 breast cancer patients, all of whom provided consent under a protocol approved by the Tokai University Hospital Institutional Review Board (Table 1). Enrollment criteria were women aged 20 years or more, no history of malignant disease in the past, and histologically confirmed breast cancer before their surgery at Tokai University Hospital, Kanagawa, Japan from Jan 2010 to July 2012. The HER2 expression level score was estimated in the main tumor by using immunohistochemistry.

We divided the patients into 3 groups: HER2 0 , patients with HER2 expression immunohistochemistry (IHC) score 0 ( $n=66)$; HER2 $1+2+$, patients with HER 2 expression IHC scores $1+$ and $2+(\mathrm{n}=89)$; and HER2 $3+$, patients with HER2 expression IHC score $3+(n=18)$. Fluoresence in situ hybridization (FISH) was conducted in case of HER2 $2+$. Healthy female donors $(n=22)$ without any malignant disease in the past were selected to provide control blood. From patients, as well as healthy donors, $7.5 \mathrm{ml}$ blood was obtained.

\section{CH401MAP peptide}

The peptide used for the stimulation was prepared as described previously [13]. Briefly, the 20-mer peptide containing the

\begin{tabular}{|l|c|}
\hline Breast cancer patients & $\mathbf{n = 1 7 3}$ \\
\hline Age (years; mean [range]) & $55.0(34-81)$ \\
\hline HER2 0/1+2+/3+ & $66 / 89 / 18$ \\
\hline DCIS/IDC/ILC/Other & $58 / 107 / 5 / 3$ \\
\hline LN metastasis +/- & $125 / 48$ \\
\hline Healthy controls & $\mathrm{n}=22$ \\
\hline Ages (years; mean[range]) & $30.9(21-42)$ \\
\hline
\end{tabular}

Table 1: Demographic and clinical characteristics of the patients and healthy donors.

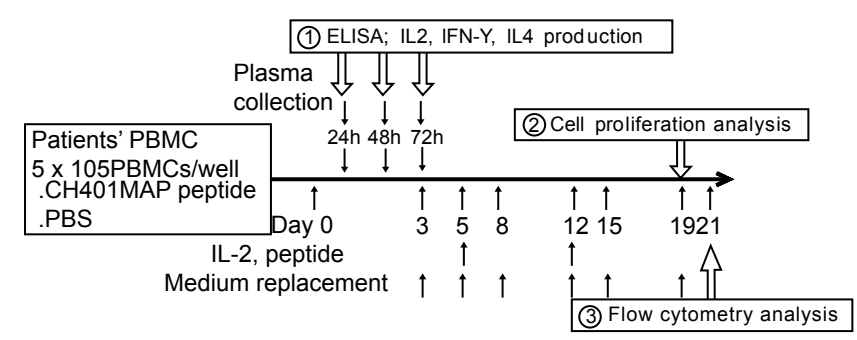

Figure 1: Protocol for peripheral blood mononuclear cell (PBMC) stimulation with CH401MAP.

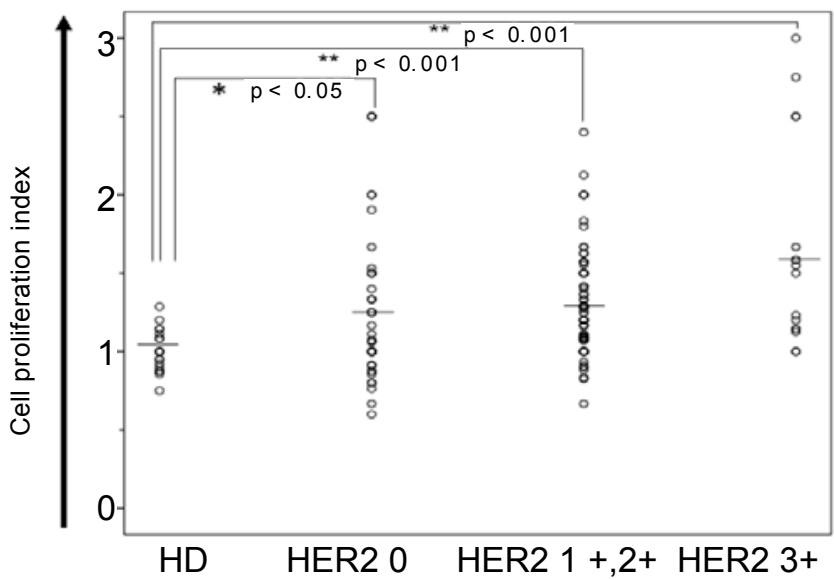

Figure 2: PBMC proliferation analysis.

Cell proliferation index of 3 patient groups (HER2 0 , HER2 1+2+, and HER2 $3+)$ and a healthy donor group (HD) are shown. HD, healthy donors $(n=22)$; HER2 0 , patients with HER2 expression immunohistochemistry (IHC) score $0(n=66)$; HER2 $1+2+$, patients with HER2 expression IHC scores $1+$ and $2+$ $(n=89)$; and HER2 $3+$, patients with HER2 expression IHC score $3+(n=18)$. Open circles represent each patient's cell proliferation index. The solid bar represents the mean value of each group. Significant difference between HD and each patient group is shown with * $(p<0.05)$ and ${ }^{* *}(p<0.001)$.

epitope of $\mathrm{CH} 401$, a monoclonal antibody (Mab) raised against HER2/neu developed by Ishida et al., was selected (N:163-182, YQDTILWKDIFHKNNQLALT) [12]. The multiple antigen peptide (MAP) was synthesized from Rink amide resin $(0.4-0.7 \mathrm{mmol} / \mathrm{g})$ using a peptide synthesizer ACT357 (Advanced ChemTech, Louisville, KY, USA), resulting in the formation of amide at the carboxyl termini. These MAPs were used for immunization and enzyme-linked immunosorbent assay (ELISA).

\section{In vitro stimulation protocol}

Blood from patients $(7.5 \mathrm{ml})$ was drawn into Vascutainer ACD tubes (NIPRO Corporation, Japan, Osaka) in the morning of the day of surgery. Peripheral blood mononuclear cells (PBMCs) from $6 \mathrm{ml}$ of the collected blood were isolated by density centrifugation $(5,000 \times g, 30$ min, $20^{\circ} \mathrm{C}$ ) using Ficoll-Hypaque (SIGMA-ALDRICH, UK, London), PBMCs were removed and washed with phosphate-buffered saline (PBS) for $5 \mathrm{~min}$ at $3,000 \times \mathrm{g}$ and $4^{\circ} \mathrm{C}$. After the cell number was determined, cells were incubated with RPMI 1640 medium supplemented with $10 \%$ human serum (immortalized, $55^{\circ} \mathrm{C}, 30 \mathrm{~min}$; Lonza, Walkersville, $\mathrm{MD}$, USA), $1 \%$ L-glutamine, $1 \%$ sodium pyruvate, $1 \%$ non-essential amino acids, and $0.5 \%$ penicillin-streptomycin in 96-well, round-bottom plates at $37^{\circ} \mathrm{C}$ in a $5 \% \mathrm{CO}_{2}$ atmosphere. All samples were treated within 
Citation: Tsuda B, Kametani Y, Goto Y, Saito Y, Suzuki Y, et al. (2012) A Human B cell Receptor Epitope-Based erbB-2 Peptide (N: 163-182) with Pan-Reactivity to the T cells of Japanese Breast Cancer Patients. J Vaccines Vaccin 3:159. doi:10.4172/2157-7560.1000159

Page 3 of 6

$12 \mathrm{~h}$. The detailed protocol for the in vitro culture of the PBMCs is shown in figure 1 . Briefly, cells were obtained from the 4 groups, HD, HER2 0 , HER $2+1+2$, and HER2 $3+$, and $1 \times 10^{5}$ cells were used for flow cytometry (FCM) analysis. The remaining cells $\left(5 \times 10^{5}\right.$ cells/well) were plated and stimulated by $\mathrm{CH} 401$ or PBS. The surface markers of the cells were analyzed 21 days after the start of stimulation.

\section{HLA typing}

The remaining volume of patients' blood $(1.5 \mathrm{ml})$ was used for HLA typing analysis. Genotyping of the HLA-A, B, and DRB1 alleles were performed using the PCR-SSOP Luminex method using LABType SSO (One Lambda Inc., Canoga Park, CA, USA), a reverse SSO DNA typing system, according to the manufacturer's instructions. A flow analyzer, LABScanTM 100, identified the fluorescent intensity of phycoerythrin on each microsphere. The determination of the HLA allele was based on the reaction pattern compared to patterns associated with published (http://www.hla.or.jp/) HLA allele sequences, which included all HLA allele types that are known until now.

\section{Peptide and MHC binding affinity simulation}

Computer algorithms accessible from internet databases, namely, SYFPEITHI developed by Rammensee H. G. et al. (http://www. syfpeithi.de/) [14] epitope prediction based on a database for HLA class I and class II prediction, BioInformatics and Molecular Analysis Section (BIMAS) developed by Parker K. C. et al. (http://www-bimas. cit.nih.gov/molbio/hla_bind/) [15] for HLA class I prediction, and Immune Epitope Database (IEDB) and analysis resource developed by Peters B. et al. (http://www.immuneepitope.org/) [16] for HLA class II prediction, were used to predict $\mathrm{CH} 401$ MAP peptide binding affinity.

\section{Immunofluorescent staining and flow cytometry analysis}

All antibodies, phycoerythrin (PE)-conjugated anti-human CD4 monoclonal antibodies (mAbs) (clone:L200), fluorescein isothiocyanate (FITC)-conjugated anti-human CD8 mAbs (clone:G42-8), peridinin chlorophyll protein complex with cyanin-5.5 (PerCP-Cy5.5)-conjugated anti-human CD3 mAbs (clone:HIT3a), allophycocyanin (APC)conjugated anti-human CD25 mAbs (clone:M-A251), PE-conjugated

Table 2a

\begin{tabular}{|c|c|c|c|c|c|c|c|}
\hline HLA type & Allele & Healthy control $(n=20705)$ & Breast cancer patients ( $n=173$ ) & SYFPEITHI score & Recognition site & BIMAS & Recognition site \\
\hline \multirow[t]{6}{*}{ A } & *24:02 & 35.9 & 29.3 & 12 & YQDTILWKDIFHKNNQLALT & - & \\
\hline & ${ }^{*} 02: 01$ & 11.5 & 11.8 & 20 & YQDTILWKDIFHKNNQLALT & 2.8 & YQDTILWKDIFHKNNQLALT \\
\hline & ${ }^{*} 02: 06 *$ & 9.2 & 16.8 & 0 & & - & \\
\hline & *11:01 & 9.1 & 8.7 & 17 & YQDTILWKDIFHKNNQLALT & 2.4 & YQDTILWKDIFHKNNQLALT \\
\hline & *31:01* & 8.6 & 20.5 & 0 & & 3.6 & YQDTILWKDIFHKNNQLALT \\
\hline & *26:01 & 7.5 & 4 & 0 & & - & \\
\hline \multirow[t]{17}{*}{ B } & *52:01 & 11.1 & 26 & - & & 13.2 & YQDTILWKDIFHKNNQLALT \\
\hline & *51:01 & 9.0 & 6.6 & 14 & YQDTILWKDIFHKNNQLALT & 4.4 & YQDTILWKDIFHKNNQLALT \\
\hline & *35:01* & 8.2 & 17.9 & - & & 1 & YQDTILWKDIFHKNNQLALT \\
\hline & *40:02 & 7.8 & 7.1 & 0 & & - & \\
\hline & *15:01 & 7.8 & 8.4 & 11 & YQDTILWKDIFHKNNQLALT & - & \\
\hline & *54:01* & 7.6 & 13.9 & - & & - & \\
\hline & *44:03 & 6.5 & 6 & 0 & & 15 & YQDTILWKDIFHKNNQLALT \\
\hline & *07:02 & 5.6 & 3.3 & 13 & YQDTILWKDIFHKNNQLALT & - & \\
\hline & *40:01 & 5.3 & 5.3 & 14 & YQDTILWKDIFHKNNQLALT & - & \\
\hline & *46:01 & 4.8 & 7 & - & & - & \\
\hline & *40:06 & 4.6 & 4.7 & & & - & \\
\hline & *39:01 & 3.4 & 3.3 & 24 & YQDTILWKDIFHKNNQLALT & 27 & YQDTILWKDIFHKNNQLALT \\
\hline & *48:01 & 2.8 & 4.4 & - & & - & \\
\hline & . & . & . & . & - & . & . \\
\hline & . & · & $\cdot$ & $\cdot$ & 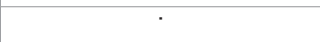 & · & $\cdot$ \\
\hline & $\cdot$ & $\cdot$ & $\cdot$ & $\cdot$ & & $\cdot$ & $\cdot$ \\
\hline & *39:02 & 0.3 & 0.6 & 11 & YQDTILWKDIFHKNNQLALT & - & \\
\hline
\end{tabular}

\section{Table 2b}

\begin{tabular}{|c|c|c|c|c|c|c|c|}
\hline$A B$ & Allele & $\begin{array}{l}\text { Healthy control } \\
\quad(n=20705)\end{array}$ & $\begin{array}{l}\text { Breast cancer patients } \\
\quad(n=173)\end{array}$ & $\begin{array}{c}\text { Breast cancer patients } \\
(n=173)\end{array}$ & Recognition site & IEDB Analysis & Recognition site \\
\hline \multirow[t]{10}{*}{ DRB1 } & *09:01 & 14.1 & 35.9 & 0 & & & \\
\hline & ${ }^{*} 04: 05 *$ & 13.7 & 8.4 & 0 & & & \\
\hline & ${ }^{*} 15: 02$ & 10.5 & 10.8 & 0 & & 4.64 & YQDTILWKDIFHKNNQLALT \\
\hline & ${ }^{*} 08: 03$ & 8.6 & 7.9 & 0 & & & \\
\hline & ${ }^{*} 15: 01$ & 7.7 & 8.7 & 20 & $\underline{\text { YQDTILWKDIFHKNNQLALT }}$ & & YQDTILWKDIFHKNNQLALT \\
\hline & ${ }^{*} 01: 01$ & 5.8 & 3.7 & 18 & YQDTILWKDIFHKNNQLALT & & YQDTILWKDIFHKNNQLALT \\
\hline & *13:02 & 5.7 & 5.5 & 0 & & 2.4 & \\
\hline & ${ }^{*} 08: 02$ & 4.2 & 3.7 & 0 & & 2.76 & \\
\hline & $* 12: 01 *$ & 3.7 & 7.5 & 0 & & & \\
\hline & *11:01 & 2.7 & 3.7 & 24 & YQDTILWKDIFHKNNQLALT & 4.33 & YQDTILWKDIFHKNNQLALT \\
\hline
\end{tabular}

Table 2: HLA alleles of the patients and healthy donors with predicted affinity scores

a)The percentages of the HLA types of both healthy donors and breast cancer patients in Japan are shown in parallel with the SYFPEITHI, BIMAS, and IEDB analyses scores. b)Recognized sequences are shown as underlined text. (-) means the allele and the peptide affinity could not be simulated by the algorithm. 
Citation: Tsuda B, Kametani Y, Goto Y, Saito Y, Suzuki Y, et al. (2012) A Human B cell Receptor Epitope-Based erbB-2 Peptide (N: 163-182) with Pan-Reactivity to the T cells of Japanese Breast Cancer Patients. J Vaccines Vaccin 3:159. doi:10.4172/2157-7560.1000159

Page 4 of 6

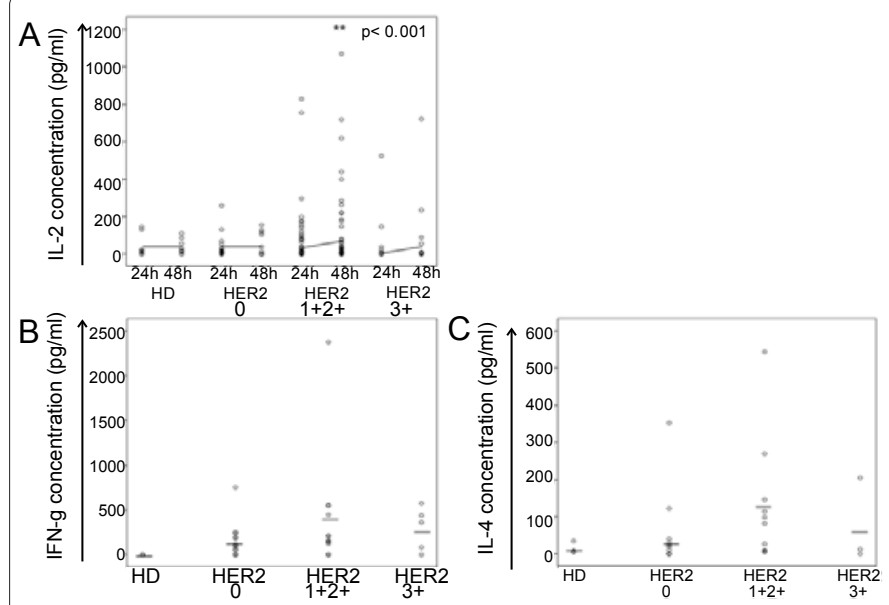

Figure 3: Cytokine secretion of patients' PBMCs stimulated with $\mathrm{CH} 401 \mathrm{MAP}$ Cytokine concentration in the supernatants of stimulated PBMCs is shown. (a) IL-2 concentration in the supernatants of PBMC culture $24 \mathrm{~h}$ and $48 \mathrm{~h}$ after the stimulation; HD $(n=9)$, HER2 $0(n=31)$, HER2 $1+2+(n=46)$, HER2 $3+(n=10)$. Open circles represent each patient's IL-2 concentration. The solid bar binds the mean values obtained either $24 \mathrm{~h}$ or $48 \mathrm{~h}$ after the stimulation. Significant differences between HD and HER2 $1+2+48$ h group are shown with ${ }^{* *}(p<0.001)$. (b) IFN-y: HD $(n=4)$, HER2 $0(n=17)$, HER2 $1+2+(n=15)$, HER2 $3+(n=5)$. (c) IL -4 of the Her2 $1+, 2+$, or $3+$ groups are shown with the healthy donor group HD $(n=4)$, HER2 $0(n=14)$, HER2 $1+2+(n=10)$, HER2 $3+(n=3)$. Solid bars represent the mean value of each group. HD; healthy donors, HER2 0; HER2 expression immunohistochemistry (IHC) score 0 patients. HER2 1+2+; HER2 expression IHC score 1+ and 2+ patients. HER2 $3+$; HER2 expression IHC score $3+$ patients.

anti-human CD4 mAbs (Clone:L200), PerCP-Cy5.5-conjugated antihuman CD3 mAbs (clone:M-A251), and FITC-conjugated anti-human CD25 mAbs (clone:BC96) were sourced from BioLegend Inc., USA, San Diego). The fixation/permeabilization concentrate, diluent, and permeabilization buffer were purchased from BD Biosciences (USA, California).

Immunofluorescent staining was performed as reported previously [12]. Fluorescence intensity of fluorochrome-labeled cells was measured by FCM (FACSCalibur, BD Biosciences) with Cell Quest Pro version 0.3.ff2b (BD Biosciences).

For the expression of Forkhead box P3 (FOXP3), the PBMC samples were subjected to intracellular staining according to manufacturer's instructions. FOXP3 Fix/Perm buffer, cell staining buffer, FOXP3 Perm buffer, and the Alexa Fluor 647-conjugated antiFOXP3 mAbs (Clone:150D) were purchased from BioLegend Inc. Fluorescence intensity of fluorochrome-labeled cells was measured by FCM (FACSCalibur, BD Biosciences) with Cell Quest Pro version 0.3.ff2b (BD Biosciences).

Final data analysis was performed by FlowJo version 7.6.1 (Tree Star, Inc.). All the data used for the analyses were acquired from the lymphocyte gate.

\section{Cytokine ELISA}

IL-2, IL-4, and IFN- $\gamma$ cytokine levels were measured by using ELISA kits (BD OptEIA Set, BD Biosciences) and Immuno LockWell Module/ Strip Plates (Thermo Fisher Scientific Inc., Denmark, Roskilde). In vitro stimulated cell supernatants were collected, and ELISA was performed according to the manufacturer's instructions. Absorbance at $450 \mathrm{~nm}$ was measured by SPECTRAmax250 (Molecular Devices, Japan, Tokyo) and analyzed by SOFTmaxPRO ver.2.2.1 (Molecular Devices,
Japan, Tokyo). As for the proliferation index, the cell number index was calculated according to the following formula: number of stimulated cells with CH401MAP/number of unstimulated cells.

\section{Statistical analyses}

The statistical significance between health donor and patients' groups was calculated using two-tailed Student's $t$ test. Values of $\mathrm{P}<0.05$ were considered statistically significant. Results are displayed as mean \pm standard deviation $(\mathrm{SD})$

\section{Results}

\section{Prediction of HLA and peptide binding affinity}

We performed HLA typing in 173 breast cancer patients to determine HLA types A, B, or DR1. Compared to Japanese healthy donors, some HLA types were significantly abundant (HLA-A ${ }^{\star} 02: 06$, HLA-A ${ }^{\star} 31: 01$, HLA-B ${ }^{\star} 35: 01$, HLA-B ${ }^{\star} 54: 01$, HLA-DRB1 ${ }^{\star}$ 09:01, HLADRB1 $\left.{ }^{\star} 04: 05, \quad H L A-D R B 1{ }^{\star} 12: 01\right) \quad$ (http://www.hla.or.jp/index.html), although the percentage of most of the HLA types found in the breast cancer patients analyzed herein were similar those of healthy donors. The scores of SYFPEITHI, BIMAS, and IEBD analyses were estimated together with the HLA typing, as shown in table 2. The scores of $97.1 \%$ of patients' HLA class I alleles and 32.5\% of patients' HLA class II alleles were higher than $10 \%$, as predicted by the SYFPEITHI simulation.

In total, $97.1 \%$ of patients were predicted to have some affinity with the CH401MAP peptide.

According to the BIMAS simulation, 59.8\% patients' class I HLAs were predicted to have some affinity with CH401MAP peptide. As for the score of IEDB analysis, $47.1 \%$ of the patients' type B HLA was scored below $10 \%$. With SYFPEITHI, BIMAS, and IEDB analyses, all the Japanese breast cancer patients examined were predicted to have affinity with CH401MAP.

The CH401MAP peptide is predicted to possess highly reactive anchor motifs of both class I and class II HLAs in Japanese breast cancer patients. The pan-reactivity is superior to that of other breast cancer vaccines [17].

\section{Lymphocyte response}

The protocol for the in vitro culture of the PBMCs is summarized in figure 1. Cells were divided into 3 experimental groups. PBMCs were stimulated with the peptide and the peptide response analyzed. Mean scores of the groups' proliferation indexes were estimated as follows: (healthy control group, $1.008 \pm 0.132$; HER2 0 group, $1.165 \pm 0.406$; HER2 1+, 2+ group, $1.255 \pm 0.331$; HER2 $3+$ group, $1.655 \pm 0.660$ ). The scores of the patient groups were significantly higher than those of the healthy control group (HER2 0 group, $\mathrm{p}<0.05$; HER2 $1+, 2+$ group, $\mathrm{p}<$ 0.01 ; Her2 $3+$ group, $\mathrm{p}<0.01$ ).

Next, we compared cytokine secretion of stimulated PBMCs with unstimulated ones. The concentration of IL-2 in the stimulated supernatants was prone to increase in all the patient groups (Figure 3a). In particular, this concentration was significantly increased in the HER2 $1+2+$ group at $48 \mathrm{~h}(\mathrm{p}<0.001)$ compared to control groups. We also measured IFN- $\gamma$ (Figure $3 \mathrm{~b}$ ) and IL-4 (Figure 3c) concentrations. The secretion of these cytokines tended to increase, although the significant difference was not observed in total (IFN- $\gamma$ : HER2 0 group, $\mathrm{p}=0.215$; HER2 1+, 2+ group, $\mathrm{p}=0.206$; Her2 $3+$ group, $\mathrm{p}=0.147$. IL-4: HER2 0 group, $\mathrm{p}=0.335$; HER2 1+, 2+ group, $\mathrm{p}=0.480$; Her2 $3+$ group, $\mathrm{p}=0.955$ ). Mean index (value of stimulated cells/value of unstimulated 

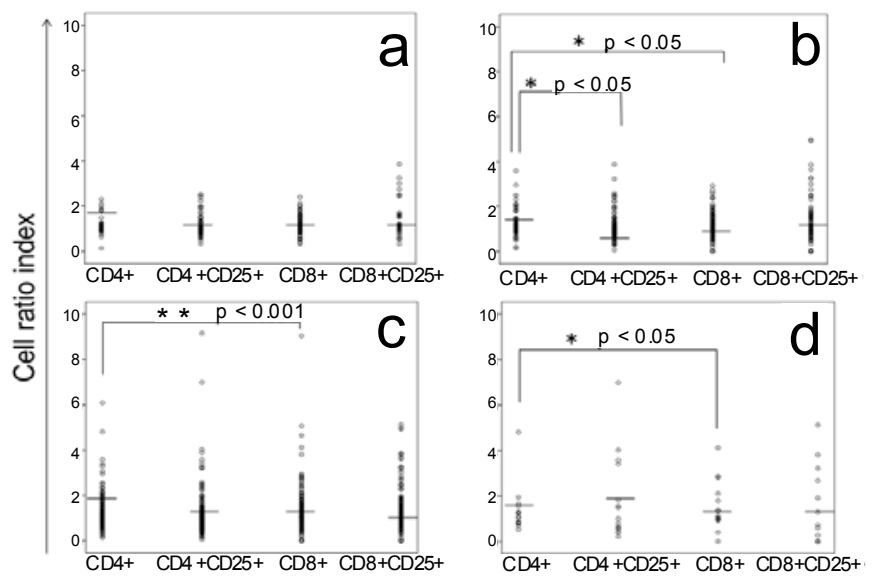

Figure 4: Cellularity of patients' PBMCs stimulated with CH401MAP. Cell ratio index of 3 patient groups (HER2 0 , HER2 $1+2+$, and HER2 $3+$ ) and a healthy donor group (HD) in lymphoid gated PBMCs are shown. (a) HD, healthy donors $(n=19)$; (b) HER2 0 , patients with HER2 expression immunohistochemistry $(\mathrm{IHC})$ score $0(n=25)$. (c) HER2 $1+2+$, patients with HER2 expression IHC scores $1+$ and $2+(n=53)$. (d) HER2 $3+$, patients with HER2 expression IHC score $3+(n=12)$. Open circles represent each patient's cell ratio index. Solid bars represent mean values of each group. Significant differences between HD and each patient group are shown with * $(p<0.05)$ and ${ }^{* *}(p<0.001)$

cells) rate was the highest in the HER2 $3+$ group in both the IFN $-\gamma$ and IL-4 series (mean values: IFN- $\gamma, 3.039$; IL-4, 0.976).

Finally, we analyzed the cellularity of stimulated PBMCs on the basis of $\mathrm{T}$ cell subsets after 21 days of stimulation. In all patient groups, the cell percentages of CD8+ cells in lymphoid gated PBMC fraction were significantly increased after the peptide stimulation, as shown in figure 4. In the HER 20 patient group, CD4+CD25+ cells were also increased. In the other groups, CD4+CD25+ cells did not increase significantly. We analyzed Foxp-3 expression simultaneously, but no increase was observed in any of the groups, suggesting that the CD4+CD25+ cells that increased in this fraction were not Treg cells (data not shown) but activated $\mathrm{T}$ cells.

\section{Discussion}

In this study, we analyzed the response of breast cancer patients' PBMCs against CH401MAP and found that it stimulated the PBMCs of most breast cancer patients to induce proliferation and cytokine production. The stimulatory effect was not limited to HER2/neu highexpression groups but it also extended to low to nil HER2/neu expression groups. The evidence that HER2/neu 0 PBMCs can also be stimulated by the peptide suggests that the peptide per se can stimulate PBMCs that have not been sensitized by the antigen previously. CH401 is a humanized monoclonal antibody against HER2/neu [12]. The epitope is different from Herceptin, as we reported previously [13]. Other monoclonal antibodies with different subtypes may stimulate other immune pathways. If monoclonal antibodies with different epitopes or different subtypes are used in parallel, a synergistic antitumor effect might be induced, while the matching of mixed monoclonal antibodies may not be so easy. However, a peptide vaccine inducing not only $\mathrm{T}$ cell activation but also peptide-specific antibody secretion is expected to induce a variety of antibody subtypes with similar specificity. Thus, the development of peptide vaccines inducing active immunity is widely accepted to be important in cancer therapy. In this context, CH401MAP may be a candidate to induce the secretion of unique antibodies and activation of $\mathrm{T}$ cell-mediated antitumor immunity at once.
On selecting the peptide as a vaccine, the presentation of the peptide on patients' HLA is a critical aspect. While peptide with epitopes of narrow restriction can be adopted on limited races, the design of the broadly restricted "promiscuous epitopes" may enable general cancer patients to accept the vaccination. Kobayashi et al. reported a HER2/ neu peptide with high degree of histocompatibility promiscuity [16] CH401MAP has similar promiscuity for not only class II but also class I HLAs, as far as the prediction by major algorithms demonstrated. Moreover, stimulation of patients' PBMCs confirmed the broad restriction of the peptide, as shown in figures 2-4. Various algorithms have been developed in the past 10 years, and we used 3 different algorithms to compare the matched peptide sequences. The algorithms suggested that the CH401 epitope-containing 20-mer peptide is categorized as a promiscuous epitope peptide.

Trastuzumab is used for treatment in patients with high HER2 expression, because the recognition of the HER2 molecule on the surface of the cancer cells is directly correlated with the HER2 expression level. However, our results suggested that in the group with lower expression of HER2 (HER2 1+2+), PBMCs were simulated to a greater extent with the peptide than were those of the HER2 3+ group (Figures 2-4). Accordingly, CH401MAP may react with HLAs of a significant number of Japanese breast cancer patients whose HER2 expression is intermediate. While this peptide possesses the B cell epitope and induces specific antibody production in a humanized mouse system [17], it activates T cells similarly to the observation in the mouse system [12]. CH401MAP is expected to induce anticancer effects in HER2-intermediate patients and prevent recurrence, suggesting its applicability to adjunctive therapy.

\section{Acknowledgments}

We are grateful to Rin Ohgiya MD, Risa Oshitanai MD, Mayako Terao MD Mizuho Terada MD, Toru Morioka MD, Takuho Okamura MD, and Naoki Niikura $\mathrm{MD}, \mathrm{PhD}$ for their clinical support and to Syuya Mori, Shin Shimada, Erina Numao, Asuka Miyamoto, Shino Ohsima and Eri Kikkawa for their excellent technical support and to Asako Ando for her supportive advice.

\section{References}

1. Sliwkowski MX, Lofgren JA, Lewis GD, Hotaling TE, Fendly BM, et al. (1999) Nonclinical studies addressing the mechanism of action of trastuzumab (Herceptin). Semin Oncol 26: 60-70

2. Kato T, Kimura T, Ishii N, Fujii A, Yamamoto K, et al. (1999) The methodology of quantitation of microvessel density and prognostic value of neovascularization associated with long-term survival in Japanese patients with breast cancer. Breast Cancer Res Treat 53: 19-31.

3. Merchant WJ, Millis RR, Smith P, Chaudary MA, Barnes DM (1999) Expression of c-erbB2 and p53 protein is similar in breast cancer from British and Japanese women. Int J Cancer 84: 278-283.

4. Slamon DJ, Clark GM, Wong SG, Levin WJ, Ullrich A, et al. (1987) Human breast cancer: correlation of relapse and survival with amplification of the HER2/neu oncogene. Science 235: 177-182.

5. Nahta R, Yu D, Hung MC, Hortobagyi GN, Esteva FJ (2006) Mechanisms of disease: understanding resistance to HER2-targeted therapy in human breast cancer. Nat Clin Pract Oncol 3: 269-280.

6. Holmes JP, Benavides LC, Gates JD, Carmichael MG, Hueman MT, et al. (2008) Results of the first phase I clinical trial of the novel II-key hybrid preventive HER-2/neu peptide (AE37) vaccine. J Clin Oncol 26: 3426-3433.

7. Carmichael MG, Benavides, LC, Holmes JP, Gates JD, Mittendorf EA, et al. (2010) Results of the first phase 1 clinical trial of the HER-2/neu peptide (GP2) vaccine in disease-free breast cancer patients: United States Military Cancer Institute Clinical Trials Group Study I-04. Cancer 116: 292-301.

8. Mittendorf EA, Clifton GT, Holmes JP, Clive KS, Patil R, et al. (2012) Clinical tria results of the HER-2/neu (E75) vaccine to prevent breast cancer recurrence in high-risk patients: from US Military Cancer Institute Clinical Trials Group Study I-01 and I-02. Cancer 118: 2594-2602. 
Citation: Tsuda B, Kametani Y, Goto Y, Saito Y, Suzuki Y, et al. (2012) A Human B cell Receptor Epitope-Based erbB-2 Peptide (N: 163-182) with Pan-Reactivity to the T cells of Japanese Breast Cancer Patients. J Vaccines Vaccin 3:159. doi:10.4172/2157-7560.1000159

9. Rammensee HG, Falk K, Rötzschke O (1993) Peptides naturally presented by MHC class I molecules. Annu Rev Immunol 11: 213-244.

10. Sette A, Sidney J (1999) Nine major HLA class I supertypes account for the vast preponderance of HLA-A and -B polymorphism. Immunogenetics 50: 201-212.

11. Lu J, Higashimoto Y, Appella E, Celis E (2004) Multiepitope Trojan antigen peptide vaccines for the induction of antitumor CTL and Th immune responses. J Immunol 172: 4575-4582.

12. Ishida T, Tsujisaki M, Hinoda Y, Imai K, Yachi A (1994) Establishment and characterization of mouse-human chimeric monoclonal antibody to erbB-2 product. Jpn J Cancer Res 85: 172-178.

13. Miyako H, Kametani Y, Katano I, Ito R, Tsuda B (2011) Antitumor effect of new HER2 peptide vaccination based on B cell epitope. Anticancer Res 31: 3361 3368.
14. Rammensee H, Bachmann J, Emmerich NP, Bachor OA, Stevanović S (1999) SYFPEITHI: database for MHC ligands and peptide motifs. Immunogenetics 50: 213-219.

15. Parker KC, Bednarek MA, Coligan JE (1994) Scheme for ranking potential HLA-A2 binding peptides based on independent binding of individual peptide side-chains. J Immunol 152: 163-175.

16. Peters B, Sidney J, Bourne P, Bui HH, Buus S, et al. (2005) The immune epitope database and analysis resource: from vision to blueprint. PLoS Biol 3: e91.

17. Kobayashi H, Wood M, Song Y, Appella E, Celis E (2000) Defining promiscuous MHC class II helper T-cell epitopes for the HER2/neu tumor antigen. Cancer Res 60: 5228

18. Kametani Y, Shiina M, Katano I, Ito R, Ando K, et al. (2006) Development of human-human hybridoma from anti-Her-2 peptide-producing $\mathrm{B}$ cells in immunized NOG mouse. Exp Hematol 34: 1240-1248. 